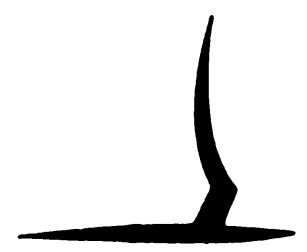

CORMELL AEROMAUTICAL LABORATORY, IMC.

BUFFALO, NEW YORK

REPORT HO. AF-1285-A-4

\title{
HYPERSONIC FLOW WITH COMBINED LEADING-EDGE BLUNTNESS \\ AND BOUNDARY-LAYER DISPLACEMENT EFFECT
}

AUGUST 1960
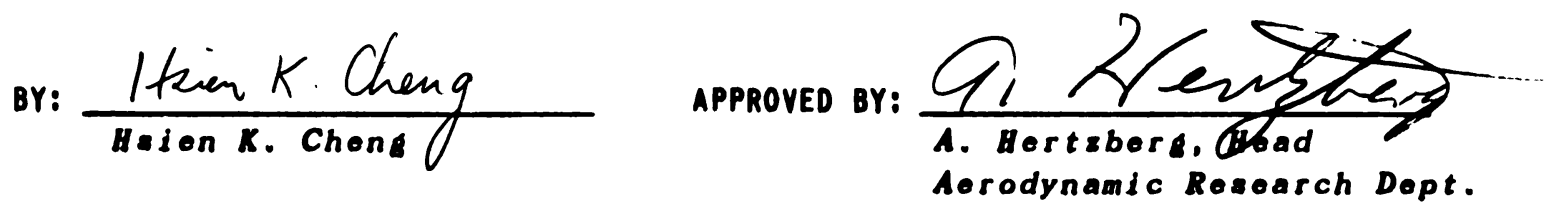

This report is based on research sponsored by the U.S. Mavy through the Office of Maval Research, Contract Monr-2653(00) 